\title{
Negative Sequence Current and Reactive Power Comprehensive Compensation for Freight Railway Considering the Impact of DFIGs
}

\author{
Diwen XIAO, Minwu CHEN, and Yinyu CHEN
}

\begin{abstract}
To solve the power quality problems caused by freight railways in weak grids with high penetration of wind generation, this paper proposes a comprehensive control method for negative sequence current (NSC) suppression and reactive power compensation. Firstly, a co-phase traction power supply system (CTPSS) is introduced, and its compensation principle is analyzed. Secondly, to bring a doubly fed induction generator (DFIG) into full play in suppressing voltage unbalance (VU) in the grid, a VU compensation model of stator is developed. Moreover, a comprehensive compensation method is presented to achieve the dynamic compensation of $\mathrm{VU}$ and reactive power. Finally, the effectiveness of the proposed approach is demonstrated using a simulation, which can fully solve the power quality issues and effectively reduce the capacity of the CTPSS.
\end{abstract}

Index Terms - Co-phase traction power supply system, doubly fed induction generator, freight railway, reactive power, voltage unbalance.

\section{INTRODUCTION}

W ITH the development of freight railway transport, the electrical sectioning issues and power quality issues represented by negative sequence current (NSC) and reactive power have restricted the safety and high-quality operation for freight railway [1]. The typical voltage unbalance factor (VUF) curve and power factor (PF) distribution is shown in Fig. 1. It can be seen that VUF has unsatisfied the power quality standard since the power grid connected with railway is weak. Meanwhile, the SS Class and HXD Class are widely used in freight railways, and the low PF (namely reactive power) is a strong challenge. Simultaneously, numerous wind turbines based on a doubly fed induction generator (DFIG) have been built along the railway for the demand of low-carbon and energysaving [2], which causes traction substation and wind turbines to be connected to a point of common coupling (PCC). On the one hand, the power quality issues of PCC would seriously interfere with the stable operation of wind turbines. On the other hand, the

Manuscript received June 30, 2021; revised August 19, 2021; accepted August 26, 2021. Date of publication September 30, 2021; date of current version September 22,2021 . This work was supported by the National Natural Science Foundation of China under Grant 51877182. (Corresponding author: Minwu Chen.)

All authors are with the School of Electrical Engineering, Southwest Jiaotong University, Chengdu 611756, China (e-mail: xdw@my.swjtu.edu.cn; chenminwu@ home.swjtu.edu.cn; yinyuchen@yahoo.com).

Digital Object Identifier 10.24295/CPSSTPEA.2021.00022

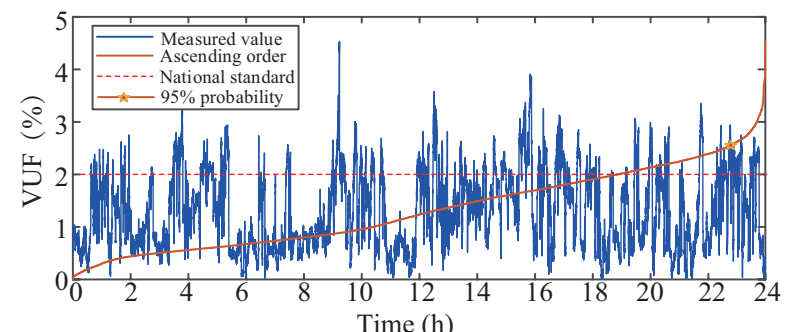

(a)

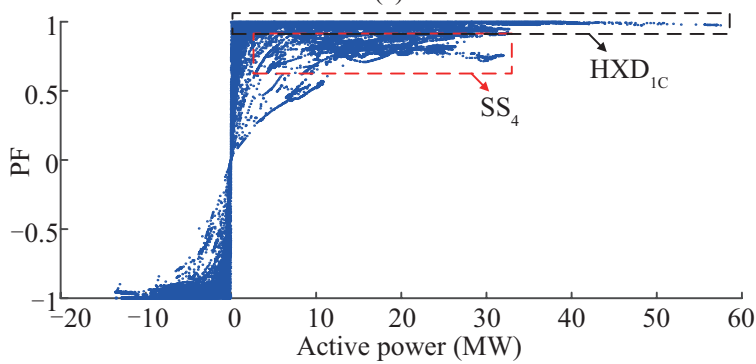

(b)

Fig. 1. Measured data of the Nanning-Kunming heavy-haul railway for 1 day. (a) Measured VUF curve. (b) Scatter diagram between PF and active power.

DFIG system has an attenuation effect on the voltage unbalance (VU) of PCC [3]-[4]. Therefore, there is an urgent demand to solve the power quality problem of freight railways considering the impact of DFIG systems.

There are a lot of technical schemes have been proposed to improve the power quality. Two approaches had been carried out in many references, i.e., install compensation device and change of power supply structure. For the first approach, compensating devices, including static var compensator (SVC), active power filter (APF) and railway power conditioner (RPC), can be added on high voltage side of the traction transformer or the traction side [5]-[7]. These devices have been widely used for NSC suppression and reactive power compensation, but the electrical sectioning issues remained. For the second approach, an advanced co-phase traction power supply system (CTPSS) scheme has been proposed and developed in [8]-[10], which can eliminate power quality problems and neutral section completely. Several compensation strategies for CTPSS have been reported in some literature [11]-[13]. However, these strategies were too stiff to be applied in the remote areas where traction power supply system (TPSS) connected with DFIGs, as the influence of DFIGs on PCC has been ignored. 
There is a focused interest in researching the impact of DFIG on power quality of PCC, especially for the impact on VU. In [14], the attenuation effect of the DFIG on VU propagation has been discussed according to the power flow analysis. Nevertheless, it not involved the mechanism analysis. [15] has established a clear mathematical relationship between the VU and DFIG, which portrayed the power performance of DFIG under the unbalance condition. Meanwhile, the active compensation capability of DFIG has been mostly used in a weak grid [16]-[17], which improved the VU of PCC by properly controlling the NSC injection.

Therefore, this paper presents a comprehensive control method for CTPSS considering the impact of DFIGs. The main contributions of this paper can be summarized as follows:

1) To address the power quality issues of freight railways, the structure of CTPSS is introduced. On this basis, a mathematical model of NSC and PF is established to analyze the compensation principle of CTPSS.

2) To bring DFIG into full play in suppressing VU in the grid, a VU compensation model of stator is built. Then, a mathematical function of NSC between PCC, CTPSS and DFIGs is derived.

3) To effectively reduce the capacity of the CTPSS, a comprehensive compensation method is presented to achieve the dynamic compensation of $\mathrm{VU}$ and reactive power, which considers the VU compensation ability of DFIG.

The rest of this paper is organized as follows: Section II analyzes the compensation principle of the CTPSS. Section III builts the VU compensation model of DFIG. In Section IV, the comprehensive control method is given. Simulation results are drawn in Sections V. Section VI concludes the paper.

\section{Compensation Performance Analysis of CTPSS}

The structure of CTPSS is made up of a single-phase traction transformer (TT) and a power flow controller (PFC) as shown in Fig. 2. The main circuit of PFC is a back-to-back converter. On the grid side, $\mathrm{PFC}$ adopts a YNd11 connection transformer and the port of PFC called $\alpha$ phase. On the traction side, PFC adopts a single-phase transformer and the port of PFC called $\beta$ phase current. The compensation performance of CTPSS is realized by the control of two ports of PFC. This section will discuss the compensation principle of the CTPSS in detail.

\section{A. NSC Compensation Method}

The relationship between three-phase current of the power grid and primary phase current of TT and YNd11 connection transformer can be derived as [12]:

$$
\left[\begin{array}{l}
\dot{I}_{A} \\
\dot{I}_{B} \\
\dot{I}_{C}
\end{array}\right]=\left[\begin{array}{cc}
\frac{1}{N_{1}} & -\frac{1}{3 N_{2}} \\
0 & \frac{2}{3 N_{2}} \\
-\frac{1}{N_{1}} & -\frac{1}{3 N_{2}}
\end{array}\right]\left[\begin{array}{c}
\dot{I}_{\mathrm{TT} 2} \\
\dot{I}_{\alpha}
\end{array}\right]
$$

where $\dot{I}_{A}, \dot{I}_{B}$ and $\dot{I}_{C}$ are the three-phase current of the power grid.

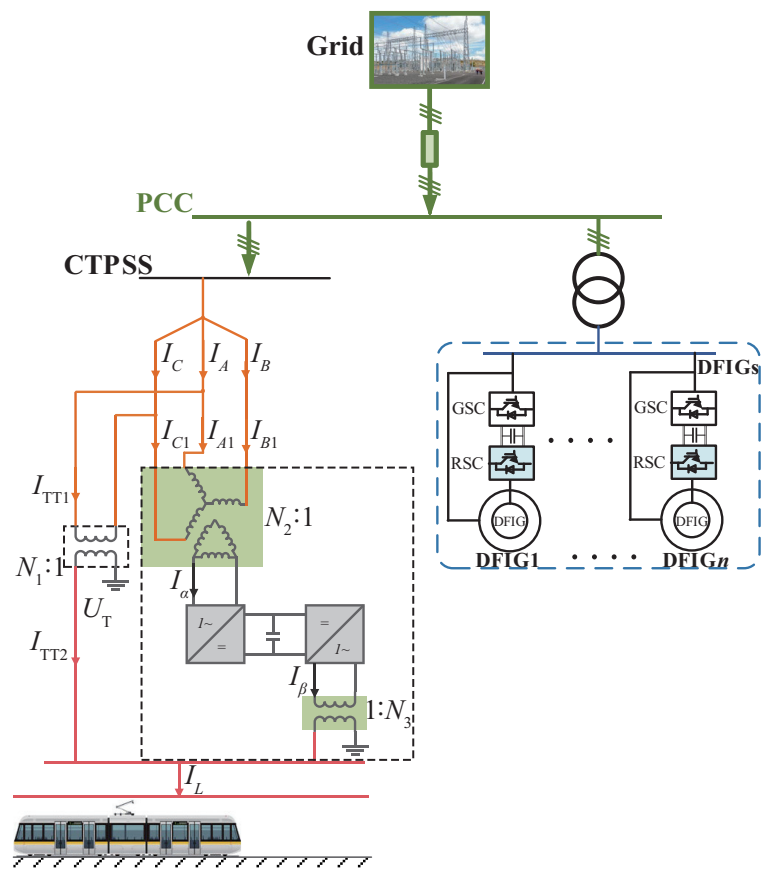

Fig. 2. Structure of the grid.

$\dot{I}_{\text {TT2 }}$ is the current in the load side of the TT. $\dot{I}_{\alpha}$ is the current of $\alpha$ phase. $N_{1}$ is the ratio of the TT, $N_{2}$ is the ratio of the YNd11 connection transformer.

According to the symmetric component method, the positive sequence and the negative sequence components of the grid can be expressed as:

$$
\left[\begin{array}{c}
\dot{I}^{+} \\
\dot{I}^{-}
\end{array}\right]=\left[\begin{array}{cc}
\frac{1-a^{2}}{3 N_{1}} & \frac{a}{3 N_{2}} \\
\frac{1-a}{3 N_{1}} & \frac{a^{2}}{3 N_{2}}
\end{array}\right]\left[\begin{array}{c}
\dot{I}_{\mathrm{TT} 2} \\
\dot{I}_{\alpha}
\end{array}\right]
$$

where $a=e^{j 120^{\circ}}$. Superscripts,+- represent the positive sequence and negative sequence components.

$\dot{U}_{A}, \dot{U}_{B}, \dot{U}_{C}$ is the three-phase voltage of power grid. $\dot{U}_{\mathrm{T}}$ is the voltage in the traction side of the TT. $\dot{U}_{\alpha}, U_{\beta}$ is the voltage of $\alpha$ phase and $\beta$ phase, respectively. Take $\dot{U}_{A}$ as a reference:

$$
\begin{gathered}
\dot{I}_{\mathrm{TT} 2}=I_{\mathrm{TT} 2} e^{-j\left(30^{\circ}+\varphi_{\mathrm{T}}\right)} \\
\dot{I}_{\alpha}=I_{\alpha} e^{-j\left(120^{\circ}+\varphi_{\alpha}\right)}
\end{gathered}
$$

where $\varphi_{\mathrm{T}}$ is the lagging phase angle of $\dot{I}_{\mathrm{TT} 2}$ against $\dot{U}_{\mathrm{T}}, \varphi_{\alpha}$ is the lagging phase angle of $\dot{I}_{\alpha}$ against $\dot{U}_{\alpha}$.

Thus, the negative sequence characteristic of CTPSS can be expressed by the complex current unbalance factor (CCUF):

$$
C C U F_{\mathrm{CTPSS}}=\frac{\dot{I}^{-}}{\dot{I}^{+}}=\frac{\frac{1}{\sqrt{3} k} I_{\mathrm{TT} 2} e^{-j\left(60^{\circ}+\varphi_{\mathrm{T}}\right)}+I_{\alpha} e^{-j\left(120^{\circ}+\varphi_{\alpha}\right)}}{\frac{2}{k} I_{\mathrm{TT} 2} e^{-j \varphi_{\mathrm{T}}}+I_{\alpha} e^{-j \varphi_{\alpha}}}
$$

where $k=U_{a} / U_{\mathrm{T}}$. 
It can be seen that the current balance is related to the traction side of the TT and the $\alpha$ phase converter of the PFC, which can be neutralized by controlling the phase angle and amplitude of $\dot{I}_{\alpha}$. Therefore, the CTPSS can achieve the full compensation of NSC and eliminate the neutral section at the exit of the substation.

\section{B. Reactive Power Compensation Method}

The active power of the locomotive is supplied by the TT and $\alpha$ phase converter of the PFC, which is absorbed from the grid. The reactive power of the locomotive is transmitted to the grid through the TT and $\beta$ phase converter of the PFC. Thus, the power flow of the CTPSS can be deduced:

$$
\left\{\begin{array}{l}
U_{\mathrm{T}} I_{\mathrm{TT} 2 p}+U_{\alpha} I_{\alpha p}=U_{\mathrm{T}} I_{\mathrm{L} p} \\
U_{\mathrm{T}} I_{\mathrm{TT} 2 q}+U_{\beta} I_{\beta q}=U_{\mathrm{T}} I_{\mathrm{L} q} \\
U_{\alpha} I_{\alpha p}=U_{\beta} I_{\beta p}
\end{array}\right.
$$

where $I_{\beta}$ is the current of $\beta$ phase and $I_{\mathrm{L}}$ is current of the locomotive. Subscripts $p, q$ represent the horizontal and vertical components, which take voltage of the same port as a reference.

Furthermore, the PF after compensation in the grid side can be derived as:

$$
P F=\frac{U_{\mathrm{T}} I_{\mathrm{L} p}}{\sqrt{\left(U_{\mathrm{T}} I_{\mathrm{L} p}\right)^{2}+\left(U_{\mathrm{T}} I_{\mathrm{TT} 2 q}+U_{\beta} I_{\beta q}\right)^{2}}}
$$

It can be seen that the reactive power compensation is performed by the $\beta$ phase converter of the PFC and can achieve the dynamic compensation of the PF.

\section{VU Compensation Perfoemance of a DFIG}

A typical DFIG system is shown in Fig. 2. The stator winding of the DFIG is directly connected to the grid; the rotor winding is connected to the grid via a back-to-back converter, which is called grid side converter (GSC) and rotor side converter (RSC), respectively. As a result, the rotor circuit can transmit power through the converters to the grid. Noting that the DFIGbased wind farm still needs a static synchronous compensator (STATCOM) to provide dynamic reactive power for supporting the voltage at the PCC [18], so this paper does not consider the reactive power compensation of the DFIG system.

Under the positive synchronous $(d q+)$ reference frame rotating at an angular speed of $\omega_{\mathrm{s}}$, the voltage and flux linkage of stator and rotor can be written as in [15]:

$$
\begin{gathered}
\dot{U}_{\mathrm{s} d q}=R_{\mathrm{s}} \dot{I}_{\mathrm{s} d q}+\frac{\mathrm{d} \dot{\psi}_{\mathrm{s} d q}}{\mathrm{~d} t}+j \omega_{\mathrm{s}} \dot{\psi}_{\mathrm{s} d q} \\
\dot{U}_{\mathrm{r} d q}=R_{\mathrm{r}} \dot{I}_{\mathrm{r} d q}+\frac{\mathrm{d} \dot{\psi}_{\mathrm{r} d q}}{\mathrm{~d} t}+j\left(\omega_{\mathrm{s}}-\omega_{\mathrm{r}}\right) \dot{\psi}_{\mathrm{r} d q} \\
\dot{\Psi}_{\mathrm{s} d q}=L_{\mathrm{s}} \dot{\mathrm{I}}_{\mathrm{s} d q}+L_{\mathrm{m}} \dot{I}_{\mathrm{r} d q} \\
\dot{\Psi}_{\mathrm{r} d q}=L_{\mathrm{m}} \dot{I}_{\mathrm{s} d q}+L_{\mathrm{r}} \dot{I}_{\mathrm{r} d q}
\end{gathered}
$$

where $R_{\mathrm{s}}$ and $R_{\mathrm{r}}$ are the resistance of stator and rotor. $I$ is the current and $\omega_{\mathrm{r}}$ is the angular speed of rotor. $L_{s}$ and $L_{r}$ are the self-inductances of stator and rotor windings, $L_{m}$ is the mutual inductance. Subscripts $\mathrm{s} d q, \mathrm{r} d q$ represent components of $d, q$ axes of stator and rotor.

By ignoring the stator and rotor resistances and considering that the stator voltage is constant in steady states, the active power and reactive power of the stator can be expressed by:

$$
\begin{aligned}
& P_{\mathrm{s}}=1.5 U_{\mathrm{s}} i_{\mathrm{s} d} \\
& Q_{\mathrm{s}}=-1.5 U_{\mathrm{s}} i_{\mathrm{s} q}
\end{aligned}
$$

The stator current can be decomposed into positive and negative sequence components, as shown below:

$$
\dot{I}_{\mathrm{s} d q}=\dot{I}_{\mathrm{s} d q+}^{+}+\dot{I}_{\mathrm{s} d q-}^{-} e^{-j 2 \omega_{\mathrm{s}} t}
$$

where subscripts,+- represent the positive and negative synchronous reference frames.

In the steady state, $\dot{I}_{\text {sd } d+}^{+}$and $\dot{I}_{\text {sdq- }}^{-}$are dc values. The positive sequence component $\dot{I}_{\text {sdq+ }}^{+}$depends on the stator active power determined by the maximum wind power tracking. The negative sequence component $\dot{I}_{\text {sd } d-}^{-}$can be controlled by the RSC according to (8)-(11). The reference value $\dot{I}_{\text {sdqref- }}^{-}$is obtained by the control centre.

$$
\left[\begin{array}{l}
\dot{I}_{A \mathrm{ref}} \\
\dot{I}_{B \mathrm{ref}} \\
\dot{I}_{\mathrm{Cref}}
\end{array}\right]=\left[\begin{array}{cc}
\sin \left(-\omega_{\mathrm{s}} t\right) & \cos \left(-\omega_{\mathrm{s}} t\right) \\
\sin \left(-\omega_{\mathrm{s}} t-\frac{2}{3} \pi\right) & \cos \left(-\omega_{\mathrm{s}} t-\frac{2}{3} \pi\right) \\
\sin \left(-\omega_{\mathrm{s}} t+\frac{2}{3} \pi\right) & \cos \left(-\omega_{\mathrm{s}} t+\frac{2}{3} \pi\right)
\end{array}\right]\left[\begin{array}{l}
\dot{I}_{\mathrm{sqref}}^{-} \\
\dot{I}_{\mathrm{sqref}-}^{-}
\end{array}\right]
$$

By using the method of symmetrical components, the negative sequence component can be expressed as:

$$
\dot{I}_{\mathrm{WFref}}^{-}=\frac{1}{3}\left(\dot{I}_{A \mathrm{ref}}+a^{2} \dot{I}_{B \mathrm{ref}}+a \dot{I}_{\mathrm{Cref}}\right)
$$

Thus, the NSC of DFIG can be written as:

$$
\begin{gathered}
\dot{I}_{\mathrm{WFref}}^{-}=\frac{1}{2}\left(\dot{I}_{\mathrm{s} q \mathrm{ref}}^{-}-j \dot{I}_{\mathrm{s} d \mathrm{ref}}^{-}-\right) e^{-j \omega_{\mathrm{s}} t} \\
\left|\dot{I}_{\mathrm{WFref}}^{-}\right|^{2} \leqslant \frac{1}{4} \max \left[\left(\left|\dot{I}_{\mathrm{s} d}-\dot{I}_{\mathrm{s} d}^{+}+\right|^{2}+\left|\dot{I}_{\mathrm{s} q}-\dot{I}_{\mathrm{s} q^{+}}^{+}\right|^{2}\right)\right]
\end{gathered}
$$

$\dot{I}_{\mathrm{WFref}}^{-}$is injected into the grid, which reflects the unbalance compensation ability of the DFIG. From (18), the $\left|\dot{I}_{\text {WFref }}^{-}\right|$is restricted to the $\dot{I}_{\text {sdq+ }}^{+}$, which illustrates that the unbalance compensation ability of the DFIG is related to the wind power.

\section{Comprehensive Compensation Method for CTPSS Connected With DFIGs}

\section{A. Compensation Principle}

1) VU Compensation

The positive sequence and negative sequence equivalent 

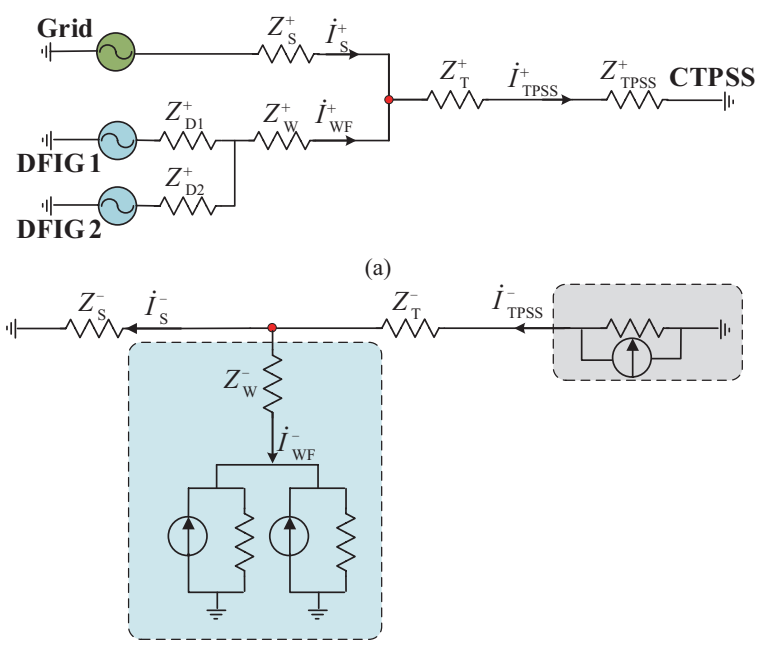

(b)

Fig. 3. Equivalent circuit. (a) Positive sequence and (b) negative sequence.

circuit of the system is established, as shown in Fig. 3. The DFIGs is represented by two DFIG systems, and the DFIG can be equivalent to an NSC controller according to the above analysis.

The positive sequence voltage and negative sequence voltage at $\mathrm{PCC}$ can be expressed as:

$$
\begin{gathered}
\dot{U}_{\mathrm{PCC}}^{-}=\dot{I}_{\mathrm{S}}^{-} Z_{\mathrm{S}}^{-} \\
\dot{U}_{\mathrm{PCC}}^{+}=Z_{\mathrm{T}}^{+} \dot{I}_{\mathrm{TPSS}}^{+}+\dot{U}_{\mathrm{TPSS}}^{+}
\end{gathered}
$$

where $Z_{\mathrm{S}}, Z_{\mathrm{T}}, Z_{\mathrm{W}}$ is the impedance of the transmission line, $Z_{\mathrm{TPSS}}$ is the impedance of the traction substation. $Z_{\mathrm{D}}$ is the impedance of DFIG.

Thus, complex voltage unbalance factor (CVUF) at PCC bus can be written as:

$$
C V U F_{\mathrm{PCC}}=\frac{\dot{U}_{\mathrm{PCC}}^{-}}{\dot{U}_{\mathrm{PCC}}^{+}}=\frac{\dot{I}_{\mathrm{S}}^{-} Z_{\mathrm{S}}^{-}}{Z_{\mathrm{T}}^{+} \dot{I}_{\mathrm{TPSS}}^{+}+\dot{U}_{\mathrm{TPSS}}^{+}}
$$

Furthermore, $\dot{I}_{\mathrm{S}}^{-}$and $\dot{U}_{\mathrm{TPSS}}^{+}$can be expressed as:

$$
\begin{gathered}
\dot{I}_{\mathrm{S}}^{-}=\dot{I}_{\mathrm{TPSS}}^{-}-\dot{I}_{\mathrm{WF}}^{-} \\
\dot{U}_{\mathrm{TPSS}}^{+}=\dot{I}_{\mathrm{TPSS}}^{+} Z_{\mathrm{TPSS}}^{+}
\end{gathered}
$$

According to (19)-(23), $C V U F_{\mathrm{PCC}}$ can be rewritten as:

$$
C V U F_{\mathrm{PCC}}=k_{1}\left(C C U F_{\mathrm{TPSS}}-k_{2} C C U F_{\mathrm{wF}}\right)
$$

where

$$
k_{1}=\frac{Z_{\mathrm{S}}^{-}}{Z_{\mathrm{TPS}}^{+}+Z_{\mathrm{T}}^{+}}, k_{2}=\frac{\dot{I}_{\mathrm{WF}}^{+}}{\dot{I}_{\mathrm{TPSS}}^{+}}
$$

From (24), it is clear that VU of PCC is contributed by downstream load, i.e., CTPSS and DFIGs. The CTPSS is the source of VU, and caused VU propagation in the grid. Assuming that DFIGs have no output NSC, in other words, the DFIGs is equivalent to impedance in negative sequence circuit, CVUF at PCC bus can be written as:

$$
C V U F_{\mathrm{PCC}}=k_{1} C C U F_{\mathrm{TPSS}} \times \frac{1}{1+\frac{Z_{\overline{\mathrm{S}}}^{-}}{Z_{\mathrm{W}}^{\overline{\mathrm{D}}}+Z_{\mathrm{D} 2}^{-}}}
$$

So the attenuation effect of the DFIGs on VU propagation is mainly expressed in the unbalance power consumption of negative sequence impedance.

Compared (24) with (27), the compensation effort of the DFIGs is considered, which reduces $C V U F_{\mathrm{PCC}}$ further.

Combining the negative sequence characteristic of CTPSS, the total compensation current reference of $\mathrm{PCC}$ can be given as:

$$
\dot{I}_{\text {ref }}^{-}=\frac{\dot{I}_{\mathrm{TPSS}}^{+}}{k_{1}} V U F_{\mathrm{PCCref}}-\dot{I}_{\mathrm{L}}^{-}
$$

where $\dot{I}_{\mathrm{L}}^{-}$is caused by locomotive.

\section{2) Reactive Power Compensation}

To fairly regulate power users and reduce the losses of the power companies, the government has strictly formulated the national standard of PF. For railway users, the PF must be higher than 0.9. Otherwise the railway transport companies will face heavy fines. Thus, the reactive power compensation equipment is indispensable to freight railway.

\section{B. Comprehensive Compensation Method}

In this paper, the PFC of CTPSS and DFIGs work together to govern the power quality issues, but the latter only participates in the NSC compensation. The compensating control of PFC and DFIGs is shown in Fig. 4.

The compensation currents calculation of the PFC have been researched in [15]:

$$
\left\{\begin{array}{l}
I_{\alpha p}^{\text {ref }}=\frac{\sqrt{3} N_{2}}{N_{1}}\left(I_{\mathrm{L} p}-m\right) \\
I_{\alpha q}^{\text {ref }}=-\frac{\sqrt{3} N_{2}}{N_{1}}\left[\sqrt{\left(\frac{I_{\mathrm{L} p}}{P F}\right)^{2}-\left(I_{\mathrm{L} p}\right)^{2}}+m\right] \\
I_{\beta p}^{\text {ref }}=N_{3}\left(I_{\mathrm{L} p}-m\right) \\
I_{\beta q}^{\text {ref }}=N_{3}\left(I_{\mathrm{L} q}-m\right)
\end{array}\right.
$$

where $m$ is the comprehensive compensation target, including VU and PF.

The compensating power of DFIG should be given as [4]:

$$
\left[\begin{array}{c}
P_{\mathrm{scom}} \\
Q_{\mathrm{scom}}
\end{array}\right]=-\frac{3}{2}\left[\begin{array}{cccc}
u_{\mathrm{s} d}^{-}+ & u_{\mathrm{sq}+}^{-} & u_{\mathrm{s} d-}^{+} & u_{\mathrm{sq}-}^{+} \\
u_{\mathrm{s} q+}^{-}- & -u_{\mathrm{s} d+}^{-} & u_{\mathrm{s} d-}^{+}- & -u_{\mathrm{s} q-}^{+}
\end{array}\right]\left[\begin{array}{c}
i_{\mathrm{s} d+}^{+} \\
i_{\mathrm{s} q+}^{+} \\
i_{\mathrm{sdref}-}^{-} \\
i_{\mathrm{s} q \mathrm{ref}-}^{-}
\end{array}\right]
$$




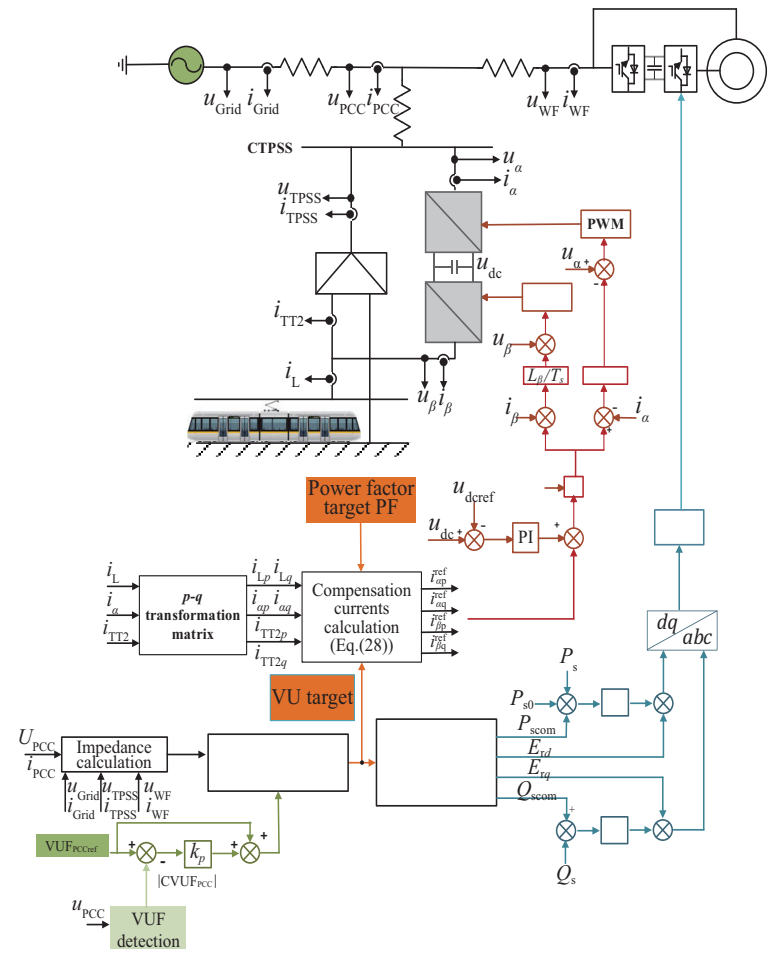

Fig. 4. Block diagram of comprehensive compensation.

TABLE I

Power Grid PARAmeters

\begin{tabular}{lc}
\hline \hline Quantity & Values \\
\hline Grid voltage & $220 \mathrm{kV}$ \\
Short-circuit capacity & $2000 \mathrm{MVA}$ \\
Line length of PCC to grid & $50 \mathrm{~km}$ \\
Line length of CTPSS to PCC & $10 \mathrm{~km}$ \\
Line length of DFIGs to PCC & $25 \mathrm{~km}$ \\
Number of DFIG & 15 \\
Apparent power of locomotive & $20 \mathrm{MVA}$ \\
\hline \hline
\end{tabular}

$P_{\mathrm{s} 0}$ is the average active power of stator determined by the maximum wind power tracking, $E_{\mathrm{r} d q}$ is the decoupling compensation component as follows:

$$
\begin{gathered}
E_{\mathrm{r} d}=-\left(\omega_{\mathrm{s}}-\omega_{\mathrm{r}}\right)\left(\frac{Q_{\mathrm{s}}}{k_{\mathrm{s}} u_{\mathrm{s} d+}}-\frac{L_{\mathrm{r}}}{L_{\mathrm{m}}} \frac{u_{\mathrm{s} d+}}{\omega_{\mathrm{s}}}\right) \\
E_{\mathrm{r} q}=-\left(\omega_{\mathrm{s}}-\omega_{\mathrm{r}}\right) \frac{P_{\mathrm{s}}}{k_{\mathrm{s}} u_{\mathrm{s} d}^{+}}
\end{gathered}
$$

where $k_{\mathrm{s}}=\frac{3}{2} \frac{L_{\mathrm{m}}}{L_{\mathrm{s}} L_{\mathrm{r}}-L_{\mathrm{m}}^{2}}$.

\section{Simulation Results}

In this section, a simulation model is built with MATLAB/ SIMULINK $^{\circledR}$ to verify the correctness of the proposed compensation control method. The power grid parameters are shown in Table I and the parameters of DFIG system and PFC are shown in Tables II and III. In the simulation model, three case studies are considered, as shown in Table IV. In case 1, the
TABLE II

DFIG PARAMETERS

\begin{tabular}{lc}
\hline \hline Quantity & Values \\
\hline Rated power & $1.5 \mathrm{MW}$ \\
Number of pole pairs & 3 \\
Rated stator voltage & $575 \mathrm{~V}$ \\
DC-link voltage & $1150 \mathrm{~V}$ \\
Stator winding resistance & $0.023 \mathrm{p.u}$. \\
Rotor winding resistance & $0.016 \mathrm{p} . \mathrm{u}$. \\
Stator leakage inductance & $0.18 \mathrm{p} . \mathrm{u}$. \\
Rotor leakage inductance & $0.16 \mathrm{p} . \mathrm{u}$. \\
Magnetizing induction & $2.9 \mathrm{p} . \mathrm{u}$. \\
\hline \hline
\end{tabular}

TABLE III

CTPSS PARAMETERS

\begin{tabular}{lc}
\hline \hline Quantity & Values \\
\hline$\alpha$ phase voltage & $27.5 \mathrm{kV}$ \\
$\beta$ phase voltage & $27.5 \mathrm{kV}$ \\
DC-link voltage & $40 \mathrm{kV}$ \\
Ratio of turns $N_{1}$ & 8 \\
Ratio of turns $N_{2}$ & $8 / \sqrt{ } 3$ \\
Ratio of turns $N_{3}$ & 1 \\
\hline \hline
\end{tabular}

TABLE IV

Case Parameters

\begin{tabular}{lccc}
\hline \hline & VUF target & PF target & Time interval $/ \mathrm{s}$ \\
\hline Case 1 & $/$ & $/$ & $0-2$ \\
Case 2 & $2 \%$ & 0.95 & $2-3$ \\
Case 3 & 0 & 0.95 & $3-4$ \\
\hline \hline
\end{tabular}

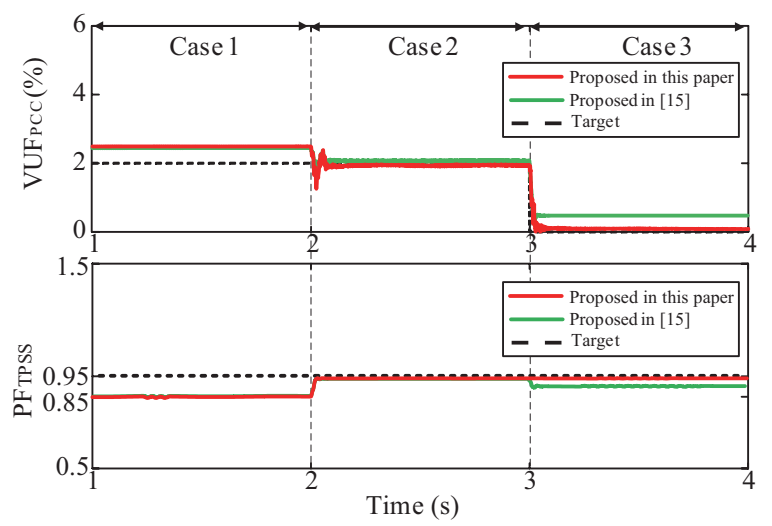

Fig. 5. Compensation results.

CTPSS and DFIGs are connected to PCC. The apparent power of the locomotive is equal to $20 \mathrm{MVA}$, and PF is 0.85 . There is no compensation in the grid before $2.0 \mathrm{~s}$. In case 2 , the VU compensation target is set at $2 \%$, and PF equals 0.98 . In case 3 , the VU target is changed to 0 .

The compensation results are shown in Fig. 5. In order to evaluate the performance and advantages of the proposed compensation method, the proposed method is compared with the compensation method in [15]. As shown in Fig. 5, it is clear that the $\mathrm{VUF}_{\mathrm{PCC}}$ is $2.5 \%$ at first, which unsatisfied the national 
TABLE V

Compensation Method Comparisons Between This Paper and Proposed in [15]

\begin{tabular}{lcc}
\hline \hline & Case 2 in [15] & Case 2 in this paper \\
\hline$\alpha, \beta$ phase voltage & $27.5 \mathrm{kV}$ & $27.5 \mathrm{kV}$ \\
$\alpha$ phase current & $124 \mathrm{~A}$ & $100 \mathrm{~A}$ \\
$\beta$ phase current & $67 \mathrm{~A}$ & $40 \mathrm{~A}$ \\
Compensation power & $5.25 \mathrm{MVA}$ & $3.85 \mathrm{MVA}$ \\
\hline
\end{tabular}

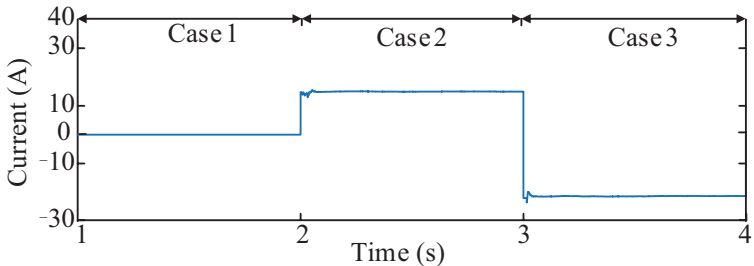

(a)

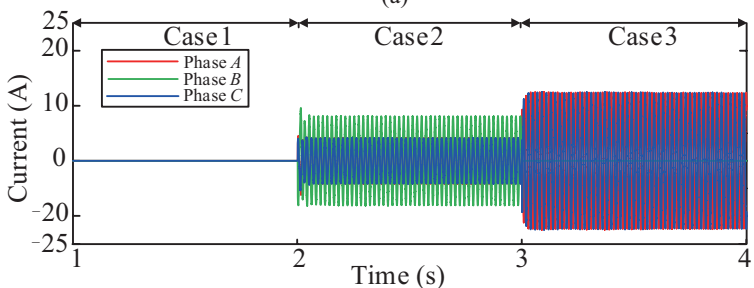

(b)

Fig. 6. VU compensation current reference. (a) PFC and (b) DFIG.
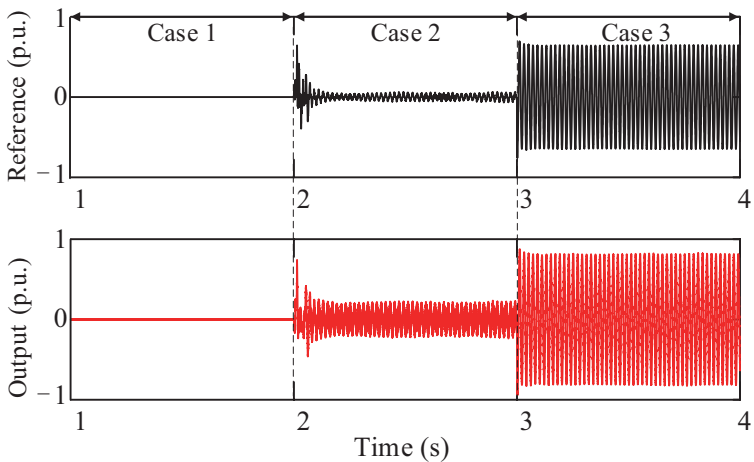

(a)
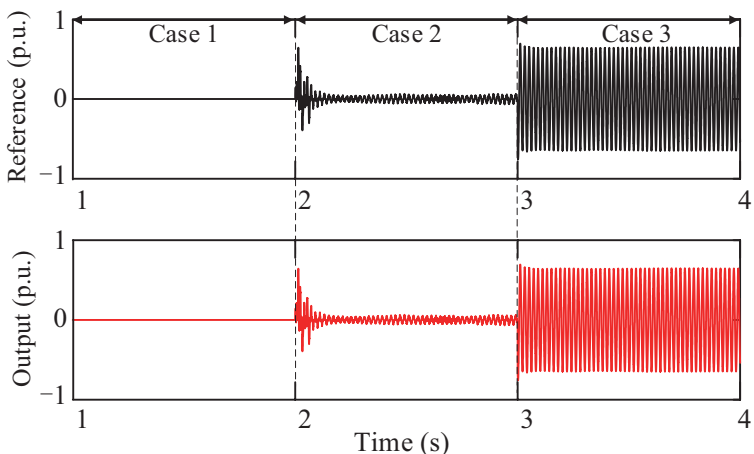

(b)

Fig. 7. Compensation current reference and actual output of two phases in PFC. (a) $\alpha$ phase and (b) $\beta$ phase.

standard of VU. In case 2, the VUF is controlled to $2 \%$ and PF equals 0.95 , which proves the effectiveness of the proposed method. The capacity comparisons of the PFC are shown in

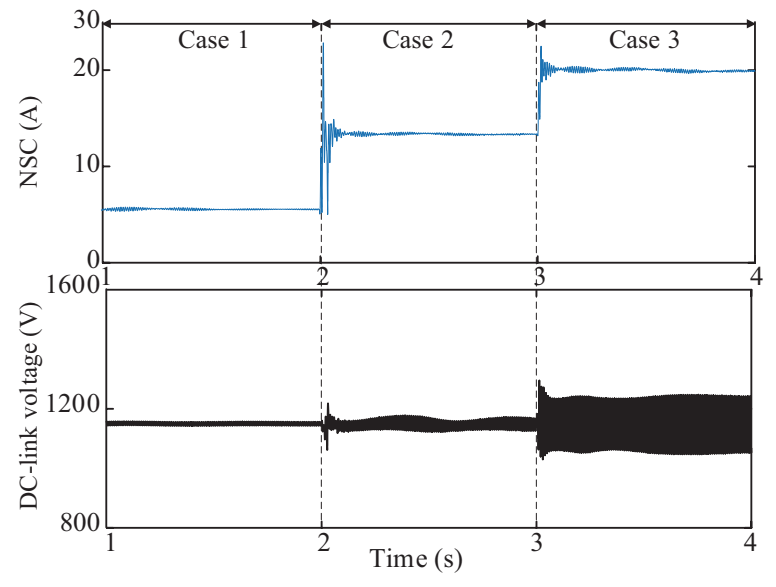

Fig. 8. Compensation performance of DFIGs.

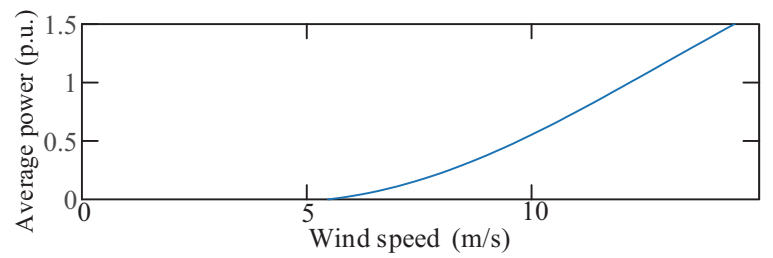

(a)

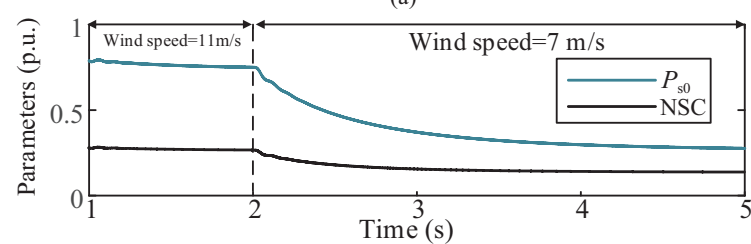

(b)

Fig. 9. The influence of wind speed. (a) maximum power coefficient tracking and (b) impact of wind speed to VU compensation.

Table V. It can be seen that the capacity is decreased by $26.7 \%$ to $3.85 \mathrm{MVA}$. This is because the VU compensation ability of DFIG is considered in this paper, which can share the effort of PFC so as to effectively reduce the capacity of PFC. In case 3 , it can be seen that the proposed method follows the change of target well, but the method in [15] cannot due to the capacity limitation of PFC.

Fig. 6 shows the VU target sharing between PFC and DFIG, which embodies they are responsible for the compensation of VU together. Fig. 7 shows the current waveform of PFC, and the values are normalized. It can be seen that the output current of two phases can accurately track references and adapt to the rapid change of the compensation target.

Fig. 8 shows the electrical parameters of DFIGs, including output NSC $\left|\dot{I}_{\mathrm{WF}}^{-}\right|$and DC-link voltage of RSC. It can be seen that DC-link voltage has the pulsation, because DFIGs outputs NSC in the stator, which will inevitably cause electromagnetic torque pulsation. Fig. 9 shows the influence of wind speed. As stated in Section IV, the average active power of DFIG generally uses the maximum power coefficient tracking method, and its power curve is shown in Fig. 9(a). The wind speed would affect $P_{\mathrm{s} 0}$ so as to affect the stator current as demonstrated in Fig. $9(\mathrm{~b})$, which qualitatively reflects the relationship between compensation performance and wind energy. 


\section{CONCLUSION}

This paper proposed a comprehensive control method of CTPSS connected with DFIGs, which suppressed the NSC and compensated the reactive power. A VU compensation model of stator is built. Secondly, based on the classical circuit theory, a mathematical function of NSC between PCC, CTPSS and DFIGs is derived. Furthermore, a comprehensive compensation method is presented to achieve the dynamic compensation of VU and reactive power. Finally, the simulation results have proved the effectiveness and good control performance of the proposed strategy.

\section{REFERENCES}

[1] L. Meng, X. Zhao, F. Tang, M. Savaghebi, T. Dragicevic, J. C. Vasquez, and J. M. Guerrero, "Distributed voltage unbalance compensation in islanded microgrids by using a dynamic consensus algorithm," in IEEE Transactions on Power Electronics, vol. 31, no. 1, pp. 827-838, Jan. 2016.

[2] P. Yao and Z. Zhu, "Industrial design and application of a railway electric special power supply," in CPSS Transactions on Power Electronics and Applications, vol. 5, no. 4, pp. 317-328, Dec. 2020

[3] M. Chindris, A. Cziker, A. Miron, H. Balan, A. Iacob, and A. Sudria, "Propagation of unbalance in electric power systems," in Proceedings of 2007 9th International Conference on Electrical Power Quality and Utilisation, Barcelona, Spain, 2007, pp. 1-5.

[4] H. Nian, T. Wang, and Z. Q. Zhu, "Voltage imbalance compensation for doubly fed induction generator using direct resonant feedback regulator," in IEEE Transactions on Energy Conversation, vol. 31, no. 2, pp. 614626, Jun. 2016

[5] J. Yuan, Y. Zhong, C. Zhang, W. Zeng, and J. Wang, "Optimal electromagnetic hybrid negative current compensation method for high-speed railway power supply system," in Journal of Modern Power Systems and Clean Energy, vol. 4, no. 1, pp. 123-134, Jan. 2016.

[6] S. Hu, S. Li, Y. Li, O. Krause, and F. Zare, "A comprehensive study for the power flow controller used in railway power systems," in IEEE Transactions on Industrial Electronics, vol. 65, no. 8, pp. 6032-6043, Aug. 2018.

[7] L. Zhao, M. Wu, Q. Liu, P. Peng, and J. Li, "Hybrid power quality compensation system for electric railway supplied by the hypotenuse of a Scott transformer," in IEEE Access, vol. 8, pp. 227024-227035, 2020.

[8] Z. Shu, S. Xie, and Q. Li, "Single-phase back-to-back converter for active power balancing, reactive power compensation, and harmonic filtering in traction power system," in IEEE Transactions on Power Electronics, vol. 26, no. 2, pp. 334-343, Feb. 2011.

[9] Q. Li, "New generation traction power supply system and its key technologies for electrified railways," in Journal of Modern Transportation, vol. 23, no. 1, pp. 1-11, Mar. 2015.

[10] Y. Liu, M. Chen, Z. Cheng, Y. Chen, and Q. Li, "Robust energy management of high-speed railway co-phase traction substation with uncertain PV generation and traction load," in IEEE Transactions on Intelligent Transportation, vol. 99, pp. 1-13, Jan. 2021.

[11] X. He, Z. Shu, X. Peng, Q. Zhou, Y. Zhou, Q. Zhou, and S. Gao, "Advanced cophase traction power supply system based on three-phase to single-phase converter," in IEEE Transactions on Power Electronics, vol. 29, no. 10, pp. 5323-5333, Oct. 2014.

[12] P. Tricoli, S. Hillmansen, C. Roberts, Q. Li, M. Chen, I. Krastev, and N. Zhao, "Modelling and performance analysis of advanced combined cophase traction power supply system in electrified railway," in IET Generation Transmission \& Distribution, vol. 10, no. 4, pp. 906-916, Mar. 2016.

[13] B. Chen, C. Zhang, C. Tian, J. Wang, and J. Yuan, "A hybrid electrical magnetic power quality compensation system with minimum active compensation capacity for $\mathrm{V} / \mathrm{V}$ cophase railway power supply system," in IEEE Transactions on Power Electronics, vol. 31, no. 6, pp. 4159-
4170, Jun. 2016

[14] O. U. Omeje, A. S. Alayande, T. O. Akinbulire, F. N. Okafor, and J. I. Ebelechi, "Propagation of current and voltage unbalance in electrical power networks," in Proceedings of 2019 IEEE PES/IAS Power, Africa, 2019, pp. 493-498.

[15] Y. Chen, M. Chen, Z. Tian, and Y. Liu, "Voltage unbalance management for high-speed railway considering the impact of large-scale DFIG-based wind farm," in IEEE Transactions on Power Delivery, vol. 35, no. 4, pp. 1667-1677, Aug. 2020.

[16] T. Wang, H. Nian, Z. Q. Zhu, H. Huang, and X. Huang, "Flexible PCC voltage unbalance compensation strategy for autonomous operation of parallel DFIGs," in IEEE Transactions on Industry Applications, vol. 53, no. 5, pp. 4807-4820, Sept.-Oct. 2017.

[17] L. Riachy, H. Alawieh, Y. Azzouz, and B. Dakyo, "A novel contribution to control a wind turbine system for power quality improvement in electrical networks," in IEEE Access, vol. 6, pp. 50659-50673, 2018.

[18] X. Zeng, J. Yao, Z. Chen, W. Hu, Z. Chen, and T. Zhou, "Co-ordinated control strategy for hybrid wind farms with PMSG and FSIG under unbalanced grid voltage condition," in IEEE Transactions on Sustainable Energy, vol. 7, no. 3, pp. 1100-1110, Jul. 2016.

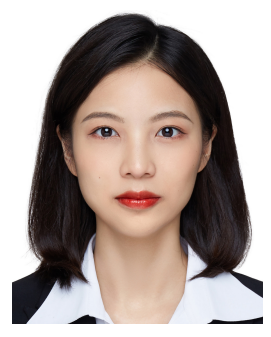

Diwen Xiao received the B.E. degree in electrical engineering from Southwest Jiaotong University, Chengdu, China, in 2020, where she is currently working toward the M.S. degree in electrical engineering. Her research interests include railway traction systems, as well as power quality assessment and control.

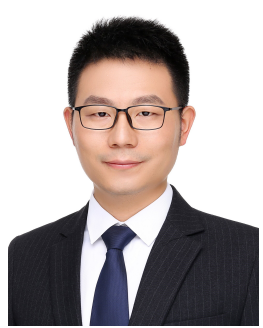

Minwu Chen received the B.E. and Ph.D. degrees in electrical engineering from Southwest Jiaotong University, Chengdu, China, in 2004 and 2009, respectively.

From 2010 to 2012, he undertook postdoctoral researches in the China Railway First Survey and Design Institute Group, Xi'an, China. Since 2018, he has been a Full Professor at the School of Electrical Engineering, Southwest Jiaotong University, and is currently the Vice Dean of School of Electrical Engineering. From 2014 to 2015, he was a Visiting Scholar at the University of Birmingham, Birmingham, UK. His research interests include new technology and power quality for railway traction systems.

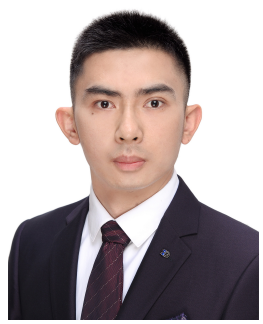

Yinyu Chen received the B.E. degree in electrical engineering from Kunming University of Science and Technology, Kunming, China, and the M.E. degree from Southwest Jiaotong University, Chengdu, China, in 2017 and 2020, respectively. $\mathrm{He}$ is currently working toward the Ph.D. degree with electrical engineering from Southwest Jiaotong University. His current research interests include railway traction systems, as well as power quality assessment and control. 